\title{
Internship Strategy for Intellectual Disability Alumni on the Inclusive Workplace Setting
}

\author{
Endang Rochyadi, Mita Apriyanti, Tjutju Soendari, Juhanaini \\ Special Education Study Program \\ Postgraduate School, Universitas Pendidikan Indonesia \\ Bandung, Indonesia \\ endangrochyadi@upi.edu
}

\begin{abstract}
Providing real-world-based experience through a job internship program provides various benefits for developing intellectual disability skills. This study aims to find the right apprenticeship strategy for intellectual disability people who attend post-school education programs and undergo internships in inclusive workplace settings. This qualitative research was carried out on four intellectual disability people who experienced work internships in two business places. Research data was obtained from observations, in-depth interviews, and documentation. The data was analyzed by using data triangulation techniques. The results showed that work internships for the mentally retarded were carried out with modifications to the stages undertaken. Modification of the stage of work internship for mentally retarded is done by modelling, mentoring, supervising, and being independent. This work phase adapts the concept of mediated learning from Vygotsky. The modified apprenticeship strategy has implications for businesses to adjust the working stages and provide trainers or work assistants for the mentally retarded.
\end{abstract}

Keywords-inclusive workplace, internship, intellectual disability.

\section{INTRODUCTION}

Adulthood is a difficult time to face for mentally disabled individuals. Demands that must be fulfilled in adulthood require a lot of effort [1]. Therefore, support from various parties is needed by the mentally challenged to successfully face challenges in adulthood. One form of support that can be given is to provide life skills for the mentally disabled. The life skills provided include skills and self-development skills.

Post-school education for mental retardation is one of the important stages that should be followed by mentally retarded people. Post-school education teaches and guides mentally retarded people to be given training and debriefing. The most important thing in post-school education is providing realworld work-based experiences through work internship programs. Career development and vocational programs in schools are very important to be taught and developed in schools in order to develop the skills and connections needed to get post-school work. In fact, adults with intellectual disabilities often do not have the opportunity to work because learning tends to only be done in the school environment without providing real experience in the field [2]. Meanwhile, actually, work experience provides a number of important benefits for people with intellectual disabilities. First, basic work skills and behaviors will be formed through practicing in a highly structured and closely controlled setting. Second, providing work experience in the world of work through an apprenticeship system can build skills such as communication, problem-solving, and asking for help. Naturally, people with disabilities who take part in a job internship will face specific challenging situations and this will give them an incentive to overcome them. In addition to developing skills, work experience is also designed to expose students to various labor settings to determine choices and interests. Direct experience provides an ideal place for them to understand various job choices [2]. Internships conducted at local home industries and designed to teach students important skills needed to work [3].

Another point to consider is that young people with mental retardation must be given the responsibility to be able to manage their own lives. These life management skills include the skills to manage finances, make the right decisions, maintain health, and utilize leisure time, develop relationships with friends, work together, and manage their transportation needs [4]. Job internships have also been carried out in accordance with the draft. Job internships are carried out by the subject in a natural setting. Job trainers who accompany the subject during a job internship are business owners. This is done at the same time to train and evaluate their performance during the internship. The results of their work were responded positively by business owners and during carrying out internships job trainers provided many new directions and knowledge to the subject. Finally, job internships are able to build activities that provide actual work experience [5].

Internships themselves are programs that have a major impact on the successful achievement of employment for graduates. Students who receive a credit to work in communities in various businesses can receive high school credit. This gives students work experience and work connections for their future and gets praise for graduation. It also provides business opportunities to work with students and open doors for businesses and students. Partnerships between secondary schools, colleges, and community businesses can be very effective. Nursing programs, welding and shops, art, and imagined work are all components of vocational programs that help students develop skills and interests in careers after 
graduation. Work-based learning opportunities related to vocational programs are recommended for high schools [6].

\section{METHOD}

This research was carried out through qualitative research methods. The subjects in this study were 4 (four) people with mental retardation who took part in work internships in two general workplaces, namely the home industry making snacks and home industries making decorative wood. The study was conducted in three months with data collected through indepth interviews with alumni, general employees, business owners, and job trainers. Data was also collected through an observation process on the process of carrying out work internships undertaken by the four subjects. Documentation studies were carried out to explore data on the initial process of conducting initial assessments of the four subjects and workplaces. The obtained data were then analyzed using data triangulation techniques. The research instrument used were observation and interview guidelines compiled by the researchers to explore data on the process of the implementation of work apprenticeship and the strategies applied to carry out work internships.

\section{RESULT AND DISCUSSION}

The implementation of the work internship in this research is a step to test the transition program that has been developed. The internship was held for three meetings in each skill. There were four subjects involved, namely $\mathrm{A}, \mathrm{D}, \mathrm{M}$, and $\mathrm{S}$. The following are the results of the implementation of the postschool transition program through the job training strategy:

\section{A. Culinary Skills}

The implementation of the internship was held for three meetings. The implementation of the work internship was carried out in the business of making fried spring roll skins located in the Cijambe area, Ujung Berung, Bandung. Alumni started the internship accompanied by researchers and business owners act as trainers as well as work supervisors. During this internship, alumni helped business owners produce fried spring rolls to be marketed before the holiday. In the implementation, the alumni conducted apprenticeship as well as received job training directly by the business owner. The internship was held on 22-24 June 2018.

On the first day of the internship, the activities carried out were observing and introducing the work environment. On the first day of work, the alumni introduced work locations and people who were met at work. Alumni were given workplace orientation by introducing equipment and materials used to make fried spring rolls. Alumni were guided directly by business owners to do work at work. They arrived at the place of business at 09.00 and were guided by business owners to be introduced to other colleagues. After that, the alumni received training and explanations from the work coach regarding the work system that will be carried out by the alumni and the techniques for making roll spring rolls that are carried out in the workplace. Alumni were introduced to the equipment at work, available facilities, and materials to be made. After all was prepared, the trainer gave a demonstration of making fried spring rolls from the beginning of the preparation of the ingredients until the mixture was ready to be fried. After the demonstration, the work trainer then guided the alumni one by one to practice step by step according to the example. On this first day, alumni began to adapt to the workplace environment. They found new things on the first day of the internship. The new thing they got about lumpia making techniques is slightly different from what is taught in school. The difference in this technique lies in the way the skin is structured after being separated, the technique of cutting the skin after rolling and sorting the fried spring rolls. Alumni did not experience difficulties with the different techniques shown. They easily learned and applied the new techniques taught. After being given training and direction, then the alumni worked independently. On the first day of work, they were still working with the coach. $M$ worked the part separating the spring roll and rolling, while $\mathrm{S}$ worked the section cutting the skin and helps fry the dough.

During breaks, $\mathrm{S}$ and $\mathrm{M}$ took a rest and communicated with people at work. The first day of the internship took place smoothly. $\mathrm{S}$ and $\mathrm{M}$ were able to adapt to a new work environment and have no difficulty in doing their work. Job trainers revealed that some of the work of $S$ and $M$ are still below production standards, but this is not a problem because some parts do require continuous habituation and training.

On the second day of the internship, S and M immediately placed their respective work units. $M$ and S started working on the part of the work that had been done like the previous day. Implementation of this second-day internship, alumni were still accompanied by work training. In each work, the work trainer still gave direction to the three alumni regarding their work which was still inappropriate.

On this second internship day, $\mathrm{M}$ and $\mathrm{D}$ were able to complete the work of rolling up a roll of seven lumpia rolls. They did it continuously without stopping. $M$ and $D$ while doing the work seemed silent and did not communicate much. While $S$ preferred to work while communicating with others or listening to music. $\mathrm{S}$ was more excited when working with friends or in groups. $\mathrm{S}$ was required to cut the skin that has been rolled and fried together with workers who help fry. $\mathrm{S}$ said that she knew she was still assisted in determining the level of maturity of fried spring rolls. Other employees helped $\mathrm{S}$ in frying and provide spices in cooked spring rolls.

On the third day of the internship, M, D, and S did the same work as the previous day. On this third day, the work trainer did not provide full assistance. The three alumni worked independently from the beginning to the end of the work process. When doing their work independently, they have been able to do but occasionally $S$ and $S$ still asked the trainer about the results of their work. The trainer only directed verbally and did not carry out intensive guidance. The three alumni did not experience difficulties in communicating well with the work coach.

\section{B. Wood Craft Skills}

The implementation of an internship for alumni A was carried out at the place of ornamental wood manufacturing in the Dago Giri area. The home-based business of making 
ornamental wood is owned by an E entrepreneur who has started a business for approximately five years. Products are marketed to Japan and several art galleries in Bandung. The internship was held for three meetings. Alumnus/ alumna A came to the place of business together with researchers. Alumnus/ alumna A was guided directly by the work coach, the business owner.

On the first day of the internship, activities carried out by A were familiar with the tools and materials and the workplace environment. A was guided directly by the work coach when conducting an introduction to the work environment. Job trainers showed various types of produced products and wood raw materials used. The trainer showed a variety of equipment used when blinding decorative wood. One by one the coach demonstrated every step of working on a product that was produced. Each stage shown by the trainer required $\mathrm{A}$ to participate in the work guided by the coach. A enthusiastically paid attention to every explanation and tried every step of the training that was coached by the trainer.

On the first day of the internship, the trainer asked A to learn to draw patterns on the wood. At this stage, A is able to make a pattern with one instruction, but the trainer still provided physical and verbal guidance because the results of work A still had to be slightly improved. However, in general, the trainer revealed that A was able to make patterns neatly. A made a picture of the hiad spoon pattern on the prepared wood sheet. After drawing the pattern in the wood, the next process that was done is cutting the wood according to the pattern. At this stage, the trainer taught how to cut wood using an electric saw machine. The trainer asked A to cut wood using the machine directly. A was able to cut wood with a machine with supervision and guidance from the work trainer.

Although the results of A's cut were still rough, but according to the work trainer for the first experiment carried out by the workers, the results of A have been said to be good and could be further trained to be smoother.

During the work process, A was able to communicate with the trainer well. When A experiences work difficulties, A could communicate with the work trainer to ask for help or ask for an opinion from a work coach. A was also able to show enthusiasm and diligence when doing work. When given the task of drawing patterns and cutting wood, A immediately worked and concentrated fully to do the work. After each work, the coach gave homework to A to complete the work of sanding the wood to work at home.

On the second day, A was taught to work on wood sandpaper. At this stage A was able to finish all instructions and examples from the work trainer. Different wood sanding movements were taught by the work coach gradually. A could understand the difference in movement and mimic the work of sanding according to the example of the work coach. On the second day, A finished working on the semi-finished product and finished finishing with around 15 decorative spoons to sand. According to the work coach, the work results from A were smooth. A also knew the time to replace sandpaper with a smoother one. However, things that have not been mastered by A were determining the level of wood smoothness and wood texture. In addition, the ability to predict precision on wood has also not been controlled by A. This did require time and habituation that was quite long and repetitive.

On the third day, A did the same work as before. A got a job to complete the round woodwork. In this round wood ampla work, A used a new sanding motion technique and a sandpaper media board. A was able to sand wood along with co-workers. The work of the sandpaper from A was not yet perfect, it was passed on by his coworkers. There were no mistakes made by A in sanding, only that the work of A still needed to be refined because of the limitations of $A$ in determining the level of fineness and precision on wood. The internship carried out by A was carried out in stages at each meeting. On the first day, A received a lot of work demonstrating from the job trainer then received guidance to work in accordance with the instructions given. On the second day, the job trainer no longer carried out the pilot but immediately carried out coaching and assistance to A. A had been given the responsibility to complete the work according to the daily target. In the third stage, A has been released and given full responsibility for completing 15 products that must be sanded and completed on that day. Job trainers were only tasked with observing the work results from $\mathrm{A}$ and providing input on the results of work done by A.

The selection of a job internship strategy aims to give alumni the work experience in the real world. Job internships were carried out using a gradual method of modeling, mentoring and mentoring, and an independent stage. The following is a work internship scheme applied:

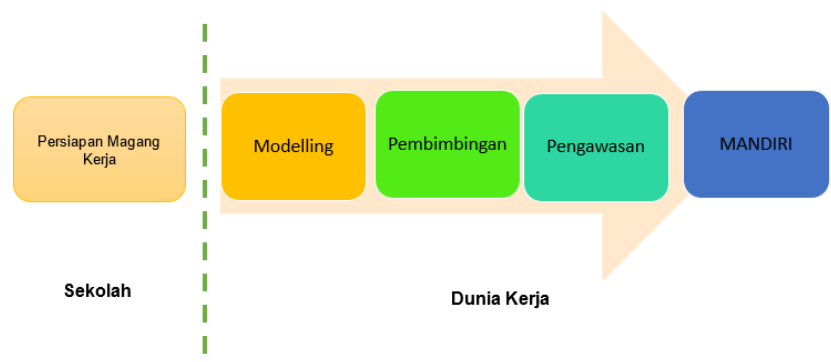

Fig. 1. Steps for Implementing Internships

The three stages have been passed by the alumni accompanied by a work coach. At the modeling stage, alumni would be given a demonstration or example from the work coach about the work to be done. At this stage, the alumni imitated the work in accordance with the instructions directly from the work coach. The second stage that would be passed is the stage of mentoring and mentoring, at this stage, the alumni would independently work in the workplace but were still given guidance and direction from the work coach. Directions and guidance could be done physically or verbally. The third stage was to do work independently, at this stage alumni would be released and given full job responsibility by the work coach. Job trainers would be tasked to overseeing the work done by alumni and providing input if the alumni communicate and ask for help. 
In the implementation of the work apprenticeship for mentally retarded, the matters were related to the alumni's needs and the modification done. Such modifications can include the removal of physical barriers and the provision of devices that help people with visual barriers, mobility, or speech, as well as changes in productivity norms, such as task modification and work schedules [7]. Work modification or job training is also designed to bring together work needs and alumni needs [8]. The following is a complete description of the guidelines for the implementation of work internships for mentally disabled people:

\section{Introduction to Work Sites}

The work location needs to be introduced to the alumni in detail. Information regarding access to transportation, the address of the workplace and buildings around the location must be explained in detail. People with disabilities can easily read, namely reading symbols that are interesting and easy to remember about the work location. This makes it easier for them to determine the type of transportation or store information about the work location. Detail location of the workplace must also be introduced such as the location of the bathroom, canteen, parking lot, place of worship, and gathering space in the workplace.

\section{Making Structured Work Schedules}

In mental retardation, a work schedule that is structured and clear is needed by the teacher or work coach. This structured work schedule contains information about the day and date, time of work from home, time should arrive at work, rest time, and time to go home. In addition, making a daily schedule should also be made a small note that is easily carried by alumni and put in the bag.

\section{E. Making Details of Work Tasks}

The details of work assignments must also be written down and explained in detail by the work coach. The work that is occupied must be detailed by drawing it through pictures. Details of work assignments are made to specify work activities carried out on each alumnus/alumna.

\section{F. Modification of Work Time}

When the mentally disabled work, the internship should be clearly demarcated. A good period of time for the mentally retarded to carry out an internship is about 3-12 months. This is done with consideration of the development that alumni have achieved based on the evaluations carried out every month. Even daily work time should be modified, such as extended work start time, longer rest or faster return time.

\section{G. Provision of Job Trainers}

Job trainers have a very influential role in mental retardation. Guidance and supervision from job trainers will affect alumni both work performance and psychologically. Moral encouragement from the coach will increase mental retardation confidence. In addition, work control by the work trainer makes mental retardation helped to complete the task more effectively. Job trainers do not have special experts. Job trainers can be taken from colleagues who are close to the alumni's work.

\section{H. Modification of Daily Work Target}

Working speed is one of the problems experienced by mental retardation when working. Work targets possessed by mentally retarded people should be distinguished from workers in general. This is related to mental retardation mentality that will feel failed and frustrated if it is not able to achieve the target set the same as the others. Need to be considered modification of the given task is simpler or longer processing time.

Participation in work-related activities provides opportunities for individuals with disabilities to connect with other individuals and their wider social and cultural environment [9]. Ideally, through work, individuals develop positive relationships that supply the support needed to manage work-related stress and encourage the development of identity [9]. More than $50 \%$ of students with mild intellectual disabilities participate in either school-specific work $(53.4 \%)$ or other paid work experience $(59.7 \%$ ) while in school; either paid or unpaid work experience at school is the most proven practice in the transition literature [10]. In addition, according to the results of this study, student involvement in schoolsponsored work or temporary paid work in school is positively related to post-school work. Given the relationship between work experience in school and work having a historical basis in the field [11], it might come as a surprise that more students with mild intellectual barriers did not report participating in this activity.

Job training services include support to help individuals prepare for the workforce, such as supplies of interest, training in job skills and basic skills, career counseling, retaliation for work or training and internships, helping to find work, and job search training. Life skills training services include support focused on developing daily life skills, such as teaching individuals how to use transportation, financial management training, and training in home self-care skills and self-care, relationships and childcare skills, and self-advocacy skill. Then, the built around activities that provide actual or connected work experience in work learning classes as examples of the work-based learning include awareness of careers and exploitation activities, assistance at work, and direct work experience through volunteers and community service, paid work and on-the-job training, and youth internships and school-based companies [5].

\section{CONCLUSION}

Providing real work experience for mental retardation is an important stage in post-school education. Giving work experience can be carried out through a workplace strategy in the general workplace. The implementation of a work internship for mentally retarded is done with several modifications to adjust to the conditions experienced by people with mental disabilities. Implementation modification is carried out with the aim of facilitating adaptability in the work environment and getting work experience that is in accordance with their needs and conditions. The modification 
is carried out on the technical part of the implementation that is related to the work process that is passed, time modification and work settings, as well as modification of the specified work targets.

\section{REFERENCES}

[1] R. G. Luecking, E. S. Fabian, K. Contreary, T. C. Honeycutt, and D. M. Luecking, "Vocational Rehabilitation Outcomes for Students Participating in a Model Transition Program," Rehabilitation Counseling Bulletin, vol. 61, no. 3, pp. 154-163, 2017.

[2] L. Lindstrom, K. A. Hirano, C. McCarthy, and C. Y. Alverson, “Just Having a Job," Career Development and Transition for Exceptional Individuals, vol. 37, no. 1, pp. 40-49, Feb. 2014.

[3] R. L. Morgan, Promoting Successful Transition to Adulthood for Students with Disabilities. London: The Guilford Press, 2016.

[4] M. Mumpuniarti, T. Suharmini, and N. Praptiningrum, "Efektivitas Program Pascasekolah Bagi Kemandirian Penyandang Disabilitas Intelektual," Jurnal PLB, vol. 1, no. 2, pp. 97-104, Dec. 2014.
[5] P. Sitlington and G. M. Clark, Transition education and services for students with disabilities. Boston: Pearson/Allyn \& Bacon, 2006.

[6] C. Mahanay-Castro, Building Transitional Programs for Students with Disabilities. New York: Rowman \& Littlefield Education Publishers, 2010.

[7] F. Shearman and C. Sheehan, "Vocational Skills Training For People With Intellectual Disabilities A Multi-Faceted Approach," Sydney Institute - Petersham Tafe, Pathways Conference, 2000, pp.1-28.

[8] S. B. Hasazi, L. R. Gordon, and C. A. Roe, "Factors associated with the employment status of handicapped youth exiting high school from 1979 to 1983," Exceptional Children, vol. 51, no. 6, pp. 455-469, Apr. 1985.

[9] D. L. Blustein, "The role of work in psychological health and wellbeing: A conceptual, historical, and public policy perspective," American Psychologist, vol. 63, pp. 228-240, 2008.

[10] L. J. Landmark, S. Ju, and D. Zhang, "Substantiated best practices in transition: Fifteen plus years later," Career Development for Exceptional Individuals, vol. 33, no. 3, pp. 165-176, 2010.

[11] K. Shuey and E. Jovic, "Disability Accommodation in Nonstandard and Precarious Employment Arrangements," Work and Occupations, vol. 40, no. 2, pp. $174-205,2013$ 